\title{
UNA APROXIMACIÓN TEOLÓGICA AL SEGUIMIENTO DE JESÚS DESDE LA INTELIGENCIA SENTIENTE
}

\section{A theological approach to the following of Jesus from setient intelligence}

\section{Artículo de reflexión derivado de investigación}

DOI: https://doi.org/10.21501/23461780.4165

Recibido: septiembre 2 de 2020. Aceptado: abril 9 de 2021. Publicado: septiembre 27 de 2021

\section{Orlando Solano Pinzón \\ Daniel Garavito Villarreal ${ }^{*}$}

\footnotetext{
${ }^{a}$ Este escrito es resultado de la búsqueda por constituir los fundamentos de la Teología de la Acción Humana (TAH) en la Facultad de Teología de la Pontificia Universidad Javeriana, Bogotá, Colombia.

* Doctor en Teología, Pontificia Universidad Javeriana, Bogotá. Docente de tiempo completo de la Facultad de Teología de la misma universidad; miembro del grupo de investigación Academia. ORCID: 0000-0003-4446626X. Correo electrónico: o.solano@javeriana.edu.co

** Doctor en Teología, Pontificia Universidad Javeriana, Bogotá, Colombia. Docente de tiempo completo de la Facultad de Teología de la misma universidad; miembro del grupo de investigación Didaskalia. ORCID: 00000003-3458-4174. Correo electrónico: dagavi22@gmail.com; garavitod@javeriana.edu.co.
} 


\section{Resumen}

Toda espiritualidad cristiana está vinculada directamente con el seguimiento de Jesús, constituyéndola como tal. El seguimiento supone movimiento, una dinámica continua de cambio que no siempre se asume en la experiencia cotidiana, para corresponder a los imperativos que la realidad plantea a la mirada creyente. La tesis que desarrolla el escrito consiste en presentar el aporte de Ignacio Ellacuría en su comprensión de la inteligencia sentiente de la realidad, al discernimiento de la acción del Espíritu para la encarnación del seguimiento histórico de Jesús y para el quehacer teológico hoy.

\section{Palabras clave}

Ignacio Ellacuría; Inteligencia; Praxis; Realidad; Seguimiento de Jesús; Teología.

\section{Abstract}

All Christian spirituality is directly linked to the following of Jesus, constituting it as such. Follow-up supposes movement, a continuous dynamic of change that is not always assumed in daily experience, to correspond to the imperatives that reality poses to the believing view. This thesis consists of presenting the contribution of Ignacio Ellacuría in his understanding of the sentient intelligence of reality, to the discernment of the action of the Spirit for the incarnation of the historical following of Jesus and for theological issues nowadays.

\section{Keywords}

Ignacio Ellacuría; Intelligence; Praxis; Reality; Following Jesus; Theology. 


\section{Introducción}

El presente artículo busca ahondar en la comprensión del seguimiento de Jesús en Ignacio Ellacuría, estableciendo una relación con la categoría "inteligencia sentiente de la realidad", que es central en su quehacer teológico, en tanto que su forma de hacer teología se concibe como teología de la realidad histórica. La tesis que se desarrollará consiste en el aporte que hace la categoría "inteligencia sentiente de la realidad" al discernimiento de la acción del Espíritu para la encarnación del seguimiento histórico de Jesús y para dinamizar el quehacer teológico hoy. Para dar cuenta de la tesis anterior, el itinerario a seguir parte de situar la comprensión del seguimiento en Ellacuría; posteriormente, abordar la comprensión de "la inteligencia sentiente de la realidad" como criterio de discernimiento para una mirada creyente de la realidad; a continuación, señalar cómo la inteligencia sentiente, al favorecer la mirada creyente de la realidad hace posible la encarnación del seguimiento histórico de Jesús y, por último, describir la identidad cristiana del quehacer teológico de Ellacuría.

\section{El seguimiento de Jesús en el pensamiento teológico de Ignacio Ellacuría}

Hablar del seguimiento de Jesús en general no representa hoy una novedad, pues a lo largo de la historia ya se han realizado un sinnúmero de reflexiones que han permitido recabar sobre los elementos que lo constituyen'. Tal es así, que entre los diferentes autores que lo abordan, hay elementos comunes que en el plano de la teoría solo llegan a darse matices diferenciadores sobre la base de los mismos fundamentos, tanto referidos a la Escritura como a los factores culturales, sociales, políticos y religiosos.

Sobre esta idea particular es posible mencionar los trabajos realizados por Jesús Espeja (1989); Jon Sobrino (1991); Luis Fernando Crespo (1991); Segundo Galilea (1995); Juan Manuel García-Lomas (1997); Carlo M. Martini (1997); Carlo M. Martini (1997); Suzanne Tunc (1999); James D. G. Dunn (2001), entre otros. 
En el caso de Ellacuría, el matiz diferenciador en su reflexión sobre el seguimiento de Jesús, lo constituye el hecho de abordarlo en relación con la categoría praxis ${ }^{2}$. En efecto, la referencia a la praxis, con la carga de significado transformador de la realidad social recibido del marxismo y la inteligencia sentiente zubiriana, permite cimentar la dinámica social en la cual se circunscribe el ser humano e integrarla con el aporte de la fe que se vive en clave de seguimiento. Esta integración obedece, según Ellacuría, a que no hay dos historias que corran en paralelo, una referida a lo social y otra que aborde el plano de la fe, sino una misma historia que el creyente está llamado a forjar desde su experiencia de fe (Ellacuría, 1993, p. 22).

Ahora bien, esta articulación entre lo histórico (Praxis) y lo teológico (Seguimiento), es decir, entre lo espiritual y lo histórico, se explicita en Ellacuría bajo una profunda sensibilidad frente a la realidad de crucifixión que hace posible que la experiencia de fe se recree. Esta sensibilidad se evidencia en las narrativas bíblicas y es de esta manera como el Texto Sagrado recupera toda su vitalidad y valor salvador para orientar el compromiso transformador de la realidad en la cual está inmerso el creyente. En este sentido, el contexto histórico de la praxis permite asumir un seguimiento coherente con las circunstancias del momento, de las cuales surgen implicaciones dentro de la apropiación que hace Ellacuría.

Como señala Sols (1999), para Ellacuría:

\footnotetext{
No hay acceso al Cristo de la fe sino a través del Jesús histórico, y que este acceso a la trascendencia del Cristo sólo fue posible por la vida que llevó, y sólo es posible al hombre más que constituyéndose en seguidor de lo que especialmente en los evangelios se nos presenta como la historicidad material de Jesús no excluido su carácter político. (p. 14)
}

\footnotetext{
La categoría praxis tiene aquí una comprensión que intenta superar las acepciones a la práctica de tipo instrumental y aplicado, que se usan en algunas teologías pastorales. Su significado es análogo a la categoría acción, en tanto incorpora una perspectiva compleja del actor en su relación personal y social. Es decir, que esta comprensión de la praxis no se satisface en la referencia a un hacer manual, porque vincula aspectos tanto de la voluntad como del ser en general.
} 
La segunda implicación, que guarda una coherencia con la anterior, establece

que cada uno de los seguidores en particular y en común trata de hacer con su propia biografía, pero en su propia historia, no tanto lo que Jesús haría, sino lo que Jesús le manda hacer, leído este mandato desde lo que él fue históricamente y a la luz de lo que su Espíritu, también a través de los signos de los tiempos, dicta en los corazones que han sido asumidos por él. Ese seguimiento tiene un evidente carácter histórico, pues no sólo se realiza en la historia, sino que hace de la historia integralmente entendida la materia misma del seguimiento. (Sols Lucía, 1999, p. 15)

En esta comprensión de historia, como señala Samour (2012), "la realidad histórica es el objeto último de la filosofía entendida como metafísica intramundana, en cuanto manifestación suprema de la realidad" (p. 42). Sols Lucía (1999) señala también que el seguimiento histórico comporta un carácter trascendente por cuanto lo tiene aquel a quien se sigue y lo tiene también el Espíritu por el cual, y con el cual se sigue, porque el seguimiento está medido y orientado por lo que debe ser el Reino de Dios, tal como lo anunció y puso en marcha Jesús (p. 15).

Esta forma de abordar el seguimiento en relación con la praxis se ajusta más a la realidad, debido a que se constituye desde una misma historia humana, más aún para Ellacuría, hay una sola historia y en ella lo divino se revela en lo humano. Sobre este particular, señala Sols Lucía (1999): "Si el seguimiento de Jesús en la actualidad histórica lleva una cierta transformación del orden de cosas, no puede ser que esa transformación del orden de cosas no tenga nada que ver con la praxis transformadora sociopolítica" (p. 237).

Desde esta mirada integradora, los elementos que hacen parte de la dinámica del seguimiento asumen una característica particular. Al respecto, la reflexión sobre el Reino de Dios que constituyó el centro del anuncio de Jesús adquiere un nuevo sentido, si la comprensión fundada en la fe se contrasta con las circunstancias políticas y sociales de seres humanos situados en unas coordenadas históricas concretas. Lo anterior significa que el seguimiento de Jesús impulsa a una praxis cristiana que incide en el horizonte socio-político. 
A partir de esta relación sin confusión entre praxis y seguimiento, Ellacuría sistematiza su comprensión del Seguimiento de Jesús, que marca una diferencia notable con las diversas maneras tradicionales de tematizarlo. En efecto, según Sols Lucía (1999), "la praxis será el espacio humano en el que se puede realizar históricamente el seguimiento creyente" (p. 240). Las ideas que se han comentado hasta este momento no han hecho otra cosa que evocar el trabajo de José Sols Lucía, quien en su tesis doctoral sistematizó los elementos constitutivos de la teología histórica de Ellacuría. El aporte del texto que se quiere ofrecer aquí, corresponde a una intuición que surge de relacionar elementos que hacen parte del teologizar de nuestro autor en cuestión, en este caso, la inteligencia de la realidad y el seguimiento de Jesús.

El desarrollo de las ideas que se exponen a continuación se ofrece al buen criterio de quienes conocen el pensamiento de Ellacuría, como un insumo para seguir profundizando en las implicaciones de su pensamiento hoy (Sols Lucía, 2014, pp. 5-26). Para quienes apenas se están iniciando en su estudio, puede servir para facilitar el acceso a la comprensión de la espiritualidad que subyace a la teología del autor, para quien "la espiritualidad cristiana es necesariamente un seguimiento de Jesús" (Ellacuría, 1983, p. 416).

\section{La inteligencia sentiente y el mirar creyente}

Según señala Samour (2014), en su estudio sobre Zubiriy el proyecto defilosofía de la liberación de Ignacio Ellacuría, tanto el estudio sobre la esencia como la trilogía sobre la Inteligencia sentiente, además de ser las dos grandes obras de Zubiri, se constituyen en la complementariedad para Ellacuría en "el entramado último y radical de su pensamiento" (p. 161). Precisamente, será la comprensión de la unidad fundamental entre el sentir y el inteligir como estructura formal, aquello que permite hablar de sentir intelectivo o intelección sentiente. Sobre este particular afirma Zubiri (1984):

Inteligencia sentiente consiste en que el inteligir mismo no es sino un momento de la impresión: el momento de la formalidad de su alteridad. Sentir algo real es formalmente estar sintiendo intelectivamente. La intelección no es intelección "de" lo sensible, sino que es intelección "en" el sentir mismo. Entonces, claro está, el sentir 
es inteligir: es sentir intelectivo. Inteligir no es, pues, sino otro modo de sentir (diferente del puro sentir). Este "otro modo" concierne a la formalidad de lo sentido. La unidad de inteligencia y de sentir es la unidad misma de contenido y formalidad de realidad. Intelección sentiente es aprehensión impresiva de un contenido en formalidad de realidad: es justo la impresión de realidad. El acto formal de la intelección sentiente es, repito, aprehensión impresiva de realidad. (p. 84)

Del párrafo anterior es claro que la aprehensión de realidad constituye el acto primero y formal del inteligir humano, capaz de instalarnos en lo real, previo al ejercicio de conceptualización, juicio o raciocinio de la inteligencia. Este aporte de Zubiri tiene una implicación teológica en tanto según Bañón Pinar (1999): "si no inteligiéramos sentientemente cosas no podríamos jamás acceder a Dios" (p. 144). Por otra parte, otro estudioso de Ellacuría y Zubiri como lo es Francisco de Aquino se pregunta: ¿Cómo se lleva a cabo la relación entre teoría y praxis en el ámbito de la inteligencia sentiente? ¿Cómo apropiar la relación entre sensibilidad e intelección? ¿En qué sentido para profundizar el carácter práxico de la teología es necesario este tránsito por la inteligencia sentiente? (De Aquino, 2010, pp. 477-499).

De la relación de complementariedad entre la teoría y la praxis se dan los pasos para que el hombre y la mujer, contextualizados históricamente, accedan a su propia praxis e intelección sentiente. Esta relación es importante porque funge como un despertar o proceso de concienciación del individuo ante la realidad, pues logra caer en la cuenta de que él siente en el acto de que es actuante. Es decir, la acción de experimentar es un acto constitutivo de sí mismo, que debe llevar a plantearse la cuestión de ¿cuál es la teoría de mi propia praxis? La inteligencia sentiente es perceptiva, pero a la vez es analítica, por lo que lo práctico depende de las formas intelectivas de la praxis. Es el momento teórico de la praxis, puesto que la analítica es la teoría que requiere una praxis responsable. En esta medida, los discursos de fundamentación teológica son teoría de la praxis.

La resignificación en la relación entre teoría y praxis de la que se ocupa la teología en la perspectiva ellacuriana de Francisco de Aquino, busca la asunción de un compromiso con la praxis más allá de una comprensión meramente confesional. En este sentido, el planteamiento ellacuriano según el cual toda 
praxis es constitutiva del Reinado de Dios en la historia, exige preguntarse por la procedencia de la praxis teológica. Por lo tanto, la perspectiva teológica de Aquino, apoyada en Zubiri y Ellacuría, es útil para el quehacer teológico, debido a que realiza una interdependencia entre teoría, praxis, intelección y sensación.

Esta comprensión de la estructura formal de la inteligencia sentiente va a ser retomada por Ellacuría, quien la profundizará como "aprehender la realidad y enfrentarse con ella" (Ellacuría, 1975, p. 18). Dicho aprehender y enfrentarse con la realidad, según el teólogo vasco, tiene una triple dimensión:

\footnotetext{
el hacerse cargo de la realidad, lo cual supone un estar en la realidad de las cosas y no meramente un estar ante la idea de las cosas o en el sentido de ellas; un estar 'real' en la realidad de las cosas, que en su carácter activo de estar siendo es todo lo contrario de un estar cósico e inerte e implica un estar entre ellas a través de sus mediaciones materiales y activas. (Ellacuría, 1975, p. 18)
}

Esta primera dimensión intelectiva es determinante para una mirada creyente, pues lejos de aislarse de la realidad o de ser indiferente 0 de proceder a partir de prejuicios, lo primero es estar de frente a la realidad, dejarse interpelar por ella, procurar comprenderla sin descuidar detalles. El énfasis en el mirar creyente obedece al carácter histórico de la revelación, según el cual la realidad expresa la acción reveladora de Dios, pues desde el acto voluntario y amoroso Él está siendo uno con el hombre. Como afirma Garavito Villarreal (2013):

sin la realidad del mundo humano la acción de Dios es inexpresable e incomprensible para el hombre, de lo que se concluye el carácter indirecto e histórico de la revelación. La realidad que manifiesta el acto revelador de Dios está constituida por la dinámica del mundo y los avatares de la historia iluminados por la fe. (p. 170)

Según lo anterior, la praxis de la revelación es la constitución de un mundo nuevo de liberación y realización para el hombre (reinado de Dios). Es la acción amorosa de Dios presente en Cristo, y cuya praxis histórica está liberada del esquema de la ley o de la retribución. Esto quiere decir que lo opuesto al esquema rígido de la ley es el amor incondicional, incluso a los enemigos como 
en el testimonio de Jesucristo. Este amor como base de la praxis cristiana es transformador, pues "Dios es el que posibilita la nueva praxis de Jesús al margen del esquema de la ley" (González, 1999, p. 265).

La segunda dimensión, según Ellacuría (1975), corresponde a

cargar con la realidad, expresión que señala el fundamental carácter ético de la inteligencia, que no se le ha dado al hombre para evadirse de sus compromisos reales, sino para cargar sobre sí con lo que son realmente las cosas y con lo que realmente exigen. (p. 18)

Es claro que el situarse de frente a la realidad no nos deja inmunes, sino que nos desafía, nos llama a la existencia y nos exige tomar posición asumiendo un modo particular de existencia. Más aún, remite a confrontar esa realidad con la tradición de fe, la cual hace posible que el mirar creyente dé razón de su esperanza en la acción, lo anterior debido a que, según Ellacuría (1979):

La fe es como la luz, gracias a la cual se hace plenamente transparente y reconocible lo que es signo real de Dios, presencia revelante de Dios [...] La fe es la visión y la fuerza cristiana que surge de e impulsa a la adecuada acción histórica [...] Habrá avance en la fe a medida que hay un avance en la acción contemplada; habrá un avance en la acción a medida que la contemplación de ella sea más creyente. (pp. 10-11)

Esta segunda dimensión de carácter ético implica asumir la responsabilidad con lo real que enfrenta una inteligencia que se realiza como histórica. Encarnar la fe para no evadir los compromisos reales, sino para cargar sobre sí con lo que realmente son las cosas y con lo que ellas le exigen.

La tercera dimensión la enuncia Ellacuría (1975) en términos de

encargarse de la realidad, expresión que señala el carácter práxico de la inteligencia, que sólo cumple con lo que es, incluso en su carácter de conocedora de la realidad y compresora de su sentido, cuando toma a su cargo un hacer real. Precisamente por esta prioridad de la realidad sobre el sentido, no hay un cambio real de sentido sin un cambio real de realidad. (p. 18)

Esta dimensión práxica hace posible que la mirada de fe de la realidad no redunde en espiritualización de la misma o en una consideración piadosa, sino que logre corresponder al clamor de la realidad con una acción encarnada que 
permite actualizar el sentido y el significado de la fe. Encargarse de la realidad es efectivamente la fidelidad con lo real, que exige una praxis que, según González (1997), está configurada por tres modos fundamentales: las acciones, las actuaciones y las actividades, cuya función es posibilitar la realización de la historia (p. 187).

Hay una serie de actividades que integran las actuaciones, por lo que en este enfoque la apropiación de una posibilidad para actuar es lo que se llama actividad. La orientación de la praxis tendrá mejores posibilidades en tanto mayor sea nuestro conocimiento de la realidad. Esto justifica que la pretensión de la actividad es fundamentalmente la de conocer la realidad, sabiendo con certeza que nunca la actividad podrá colmar la totalidad de lo real: "No decidimos lo que es la realidad en función de nuestra actividad, sino que nuestra actividad necesita conocer la realidad para decidir cómo actuar" (González, 1997, p. 98). En otras palabras, Benítez (s.f.) al hablar del legado eclesiológico en Ellacuría, "lo que deben perseguir los verdaderos seguidores de Jesús es la mayor realización posible del Reino de Dios en la historia" (párr. 6).

La lógica de estas tres dimensiones que buscan dar cuenta de la inteligencia sentiente de la realidad es recogida de forma sencilla por Sobrino (1992) en los siguientes términos:

se conoce mejor la realidad cuando se opera sobre ella; se conoce mejor lo que es el reino de Dios cuando se intenta construirlo; se conoce mejor lo que es el pecado cuando se intenta erradicarlo. Dicho en forma bíblica, se conoce a Dios cuando se practica la justicia, se conoce cuando se ama. Dicho en forma técnica, se conoce la realidad cuando, además de hacerse cargo de la realidad (momento noético) y de cargar con la realidad (momento ético), uno se encarga de la realidad (momento práxico). (p.68)

Como aporte al trabajo de Ellacuría de identificar y desarrollar las tres dimensiones de la estructura de la inteligencia sentiente, el mismo Sobrino, quien tuvo ocasión de compartir directamente con Ellacuría durante su vida, va a señalar una cuarta dimensión. En sus escritos titulados "El pueblo crucificado" y "La civilización de la pobreza", comenta lo siguiente: "Por mi parte he 
añadido -más por experiencia e intuición que por reflexión teórica- una cuarta dimensión: "dejarse cargar por la realidad" (dimensión de gracia)" (Sobrino, 2005, p. 210).

La referencia a esta cuarta dimensión, aunque no es de Ellacuría, la abordamos porque nos permite ampliar la comprensión de la dinámica que está a la base de la mirada de fe de la realidad. Como bien señala Sobrino (2006), esta dimensión surge de la experiencia y la intuición fruto del trabajo en medio de las comunidades que vivían y aún viven bajo el flagelo de la pobreza y la opresión (p. 246).

Dejarse cargar por la realidad que se traduce como la apropiación de la gratuidad que viene de lo real, permite sintonizar con la revelación histórica de Dios. Lo anterior, debido a que la apropiación de la dimensión de lo divino en el ser de la persona (autoconciencia), que posibilita la mirada de fe, es un don de Dios. Todo lo que nos es posible conocer de Dios en el ejercicio de aprehender la realidad histórica, no es resultado de un mero esfuerzo de la razón sino algo dado gratuitamente. En efecto, toda mirada de fe de la realidad remite a caer en la cuenta de la gratuidad de lo dado, en este caso, la irrupción del misterio.

En relación con lo anterior, es posible concluir que la inteligencia sentiente de la realidad, que se despliega en el hacerse cargo, cargar y encargarse de la realidad, constituye un criterio de discernimiento para la mirada de fe, en tanto que hace posible la aprehensión de la realidad y desde ella, reconocer la irrupción del misterio, en tanto que la revelación de Dios es histórica. En este caso, como afirma Garavito (2013),

Dios es siempre acto que está presente en la historia humana a través de los actos que la integran. Aunque sobrepasa los límites de nuestra comprensión, se revela en esas condiciones finitas con el objeto de que sea captado y asumido históricamente. (p. 169)

Frente a este aporte que hacen las tres dimensiones antes mencionadas, la dimensión de la gracia, a la que hace alusión Sobrino, permite comprender un dato no menor, que en el apartado siguiente podrá ser mejor comprendido, esto es, que sí nos es posible acceder al misterio es fundamentalmente porque Él mismo gratuitamente lo ha manifestado. 


\section{La inteligencia sentiente de la realidad y el seguimiento histórico de Jesús}

Las ideas que hemos expuesto hasta este momento permiten contextualizar la pretensión del presente apartado. En primer lugar, porque han situado la particularidad de la reflexión de Ellacuría sobre el seguimiento de Jesús y, en segundo lugar, porque han permitido explicitar las particularidades de las dimensiones de la inteligencia sentiente de la realidad en función del mirar creyente de la realidad, que es propio de quien sigue a Jesús.

Para el desarrollo del presente apartado, tendremos como referente la afirmación que hace Sols Lucía (2014) sobre la comprensión del seguimiento de Jesús en Ellacuría: "El seguimiento es un seguimiento histórico del Jesús que hizo presente la divinidad en la historia" (p. 15). Para tal efecto, tomaremos como referente el pasaje bíblico de la multiplicación de los panes, buscando de esta manera mostrar la particularidad que asumió el seguimiento de Jesús, desde la inteligencia de la realidad en el mismo Ellacuría y para nosotros hoy, como se evidencia en la siguiente tabla:

Tabla 1

\section{La multiplicación de los panes}

En aquel tiempo, vio Jesús una gran multitud y tuvo compasión de ellos, porque eran como ovejas que HACERSE CARGO no tienen pastor, y comenzó a enseñarles muchas cosas. Y como fuese muy tarde, se llegaron a Él sus discípulos y le dijeron: «Este lugar es desierto y la hora es ya pasada; despídelos para que vayan a las granjas y aldeas de la comarca a comprar de comer».

YÉll les respondió y dijo: «Dadles vosotros de comer». Y le dijeron: «¿Es que vamos a comprar doscientos denarios de pan para darles de comer?». Él les contestó: "¿Cuántos panes tenéis? Id a verlo». Y CARGAR habiéndolo visto, dicen: "Cinco, y dos peces».

ENCARGARSE

Entonces les mandó que se acomodaran todos por grupos de comensales sobre la hierba verde. Y se sentaron en grupos de ciento y de cincuenta. Y tomando los cinco panes y los dos peces y levantando los ojos al cielo, bendijo, partió los panesy los dio a sus discípulos para que los distribuyesen; también partió los dos peces para todos. Y comieron todos hasta que quedaron satisfechos. Y recogieron doce cestas llenas de los trozos que sobraron de los panes y de los peces. Los que comieron eran cinco mil hombres.

Nota: Biblia de Jerusalén, (2006), Mc. 6, 34-44. 


\section{Hacerse cargo de la realidad}

El primer paso para asumir de manera encarnada el seguimiento es ver la realidad tal cual es. Si bien en la dinámica del seguimiento el punto de partida lo constituye la radicalidad de la llamada, dicha llamada tiene hoy como lugar de gestación la honestidad con la realidad. Pero no se trata de una mirada superficial, sino ponerse de frente a la realidad, buscando comprender aquello que la realidad quiere manifestar. En el caso de Ellacuría, por su labor como intelectual, este primer momento noético revestía gran hondura y rigurosidad al punto de poner la academia al servicio de la comprensión de la realidad que se vivía en aquel entonces.

Del testimonio de Ellacuría sigue vigente el talante con el cual busca habérselas con la realidad de manera rigurosa. Las mediaciones para buscar hacer inteligible el dato de la realidad pueden variar de acuerdo a las posibilidades y capacidades de las personas, pero nunca la disposición a dejarse afectar por la realidad, verla tal cual es sin prejuicios ni omisiones.

En el pasaje de Marcos, que hemos referido anteriormente, está clara la disposición de Jesús para ponerse de frente a la realidad. Dentro de este gesto es significativo el hecho de ver la multitud, lo cual nos permite comprender la importancia del lugar teologal desde dónde situarse de cara a la realidad. En el caso de Jesús, la multitud estaba constituida por pobres, enfermos, desempleados, viudas, niños, quienes padecían las inclemencias de un orden social opresor, excluyente e injusto. Jesús se sitúa del lado de quienes padecen las consecuencias de la opresión, que los hace más vulnerables y amenaza más directamente sus vidas. Dicha actitud actualiza el texto paradigmático del Éxodo, en el cual Dios mismo frente a la realidad de la opresión no es indiferente a los clamores de quienes la padecen, como se menciona en Éxodo 3: 7-9:

\footnotetext{
Bien vista tengo la aflicción de mi pueblo en Egipto, y he escuchado su clamor en presencia de sus opresores; pues ya conozco sus sufrimientos. He bajado para librarle de la mano de los egipcios... Así pues, el clamor de los israelitas ha llegado hasta mí y he visto además la opresión con que los egipcios los oprimen. (Biblia de Jerusalén, 2006)
} 
En el caso de Ellacuría, dicha multitud mantenía una analogía de proporción con la descrita anteriormente, salvo que el lugar era El Salvador y el contexto la situación de opresión marcada por un régimen de dictadura militar. El lugar asumido por el teólogo vasco, en continuidad con la del mismo Jesús, fue el de las víctimas de la opresión, lo cual le permitió actualizar el sentido de la llamada al seguimiento y configurar un modo particular de respuesta.

El testimonio de Jesús, que hace eco en Ellacuría en su manera de acoger la llamada al seguimiento, es determinante para encarnar el seguimiento hoy. Tal vez en la actualidad, más que en el pasado, hay obstáculos que se han tecnificado para impedir el acceso a la realidad, tal es el caso de 'la posverdad'3 y las 'fake news', que suponen una dificultad muy importante para las personas a la hora de diferenciar los hechos reales de los hechos de ficción. La búsqueda de la verdad ya no es tomada como un valor per se, pues lo que importa es sacar beneficio de todo, la mentira puede ser validada si responde a intereses de grupos que buscan asumir un rol de control político, social, económico, religioso. Ante esta dificultad, el situarse de frente a la realidad y acceder a ella de primera mano, puede asegurar una adecuada inteligencia sentiente de la misma.

\section{Cargar la realidad}

Es importante aclarar que este esfuerzo por diferenciar las dimensiones de la estructura de la inteligencia sentiente solo busca aportar una mayor comprensión de la dinámica que está a la base de la aprehensión de la realidad y su vinculación con el seguimiento, para enfatizar su carácter histórico. El segundo paso para asumir de manera encarnada el seguimiento es dejarse afectar por la realidad tal cual es. La llamada exige la radicalidad de la respuesta, pero a ella se llega gracias al fruto de la honestidad con lo real. En el

La RAE ofrece la siguiente definición de posverdad: "Distorsión deliberada de una realidad, que manipula creencias y emociones con el fin de influir en la opinión pública y en actitudes sociales. Los demagogos son maestros de la posverdad".

El Cambridge Dictionary ofrece la siguiente definición: "false stories that appear to be news, spread on the internet or using other media, usually created to influence political views or as a joke" (Cambridge Dictionary (s.f.) Fake news. https://dictionary.cambridge.org/es/diccionario/ingles/fake-news). 
caso de Ellacuría, dada su experiencia de fe, el hacerse cargo de la realidad que vivían las mayorías empobrecidas de El Salvador, le llevó a hacerse solidario de la causa de las víctimas del régimen militar.

Esta forma de inteligir sintiendo y sentir inteligiendo la realidad conecta con el pasaje bíblico de Marcos que venimos comentando. Frente a una multitud que se encuentra vulnerable, sufriente, agobiada por la exclusión social y la injusticia, como ovejas sin pastor, Jesús no es indiferente y dicha realidad lo lleva a sentir compasión. En el caso de Ellacuría, el riguroso esfuerzo intelectual por hacerse cargo de la realidad suscitó en él el sentimiento de solidaridad con las víctimas de la dictadura, con un ingrediente adicional propio de la fe, en tanto que el sentimiento de solidaridad con el pueblo salvadoreño le permitía identificarse con el mismo Jesús, pues respondía a la invitación de Pablo de "tener los mismos sentimientos de Cristo" (Biblia de Jerusalén, 2006, Fil 2, 5).

La identidad con Cristo, que hace posible el seguimiento, no es algo ajeno a la realidad, sino que es posibilitada por el habérselas con ella de la manera más honesta posible. Es esta identidad con Cristo en sus sentimientos más hondos, aquello que permite comprender que a la llamada al seguimiento que se manifiesta en el hacerse cargo de la realidad, corresponde una respuesta radical propia del cargar la realidad. Esta manera de comprender la identidad con Cristo es necesaria para explicitar el carácter histórico que implica encarnar el seguimiento hoy.

\section{Encargarse de la realidad}

El tercer paso para asumir de manera encarnada el seguimiento es encargarse de la realidad. La llamada exige no sólo la radicalidad sino también la concreción de la respuesta y, en Ellacuría, dicha concreción está ligada a un amplio elenco de acciones que buscaron hacer concreto el sentimiento de solidaridad con las víctimas de la opresión que vivía el pueblo salvadoreño. 
El pasaje del evangelio de Marcos que venimos comentando termina con la invitación de Jesús a dar de lo que se tiene para contribuir a saciar el hambre de la multitud necesitada. Ante la poca disposición de los discípulos, él mismo toma la comida, la bendice y la reparte, de tal modo que alcanzó para todos y sobró. En el caso de Ellacuría, el encargase de la realidad fue asumido desde su experiencia de fe como búsqueda por saciar el hambre y la sed de justicia del pueblo salvadoreño, cuyo sufrimiento injusto le llevó a Ellacuría a interpretarlo como un pueblo crucificado. El compromiso transformador por bajar de la cruz al pueblo crucificado, se constituyó en su causa cotidiana, pues no era concebible confesar la fe en medio de esa realidad sin un compromiso real en función de la transformación de la misma. Sobre este particular afirma que "si el seguimiento de Jesús en la actualidad histórica lleva una cierta transformación del orden de cosas, no puede ser que esa transformación del orden de cosas no tenga nada que ver con la praxis transformadora sociopolítica" (Sols Lucía, 1999, p. 237).

Este compromiso transformador que hace, concreta la inteligencia sentiente de la realidad, posibilita la adecuada encarnación del seguimiento, no sólo ayer sino hoy y siempre. Si seguir a Jesús define al cristiano y si al asumir el seguimiento participamos del dinamismo salvador revelado en sus hechos y palabras, dicho dinamismo deberá contribuir a la humanización de la realidad para hacer posible que todos podamos vivir como hijos e hijas en el Hijo de Dios y hermanos los unos de los otros. Lo anterior obedece a que, para Ellacuría (1977):

Una salvación histórica que no traiga consigo la solidaridad humana no es la salvación histórica, pero no es tampoco salvación de la historia; una salvación histórica que no abra al hombre hacia lo que en él le trasciende no puede ser el signo de Dios, no puede ser historia de la salvación, pero tampoco puede ser plena salvación de la historia. (p. 284) 


\section{Dejarse cargar por la realidad}

Estaúltima dimensión de gracia no tiene fundamento en un postulado filosófico, pero ello no le quita su fuerza y su verdad, pues se sitúa en el único plano de la fe. Como veíamos en un apartado anterior, el mismo Sobrino, quien acuña el término, reconoce que surge de la experiencia en el trabajo mancomunado al interior del pueblo crucificado y como una intuición de fe. En efecto, es descubrir que en dicho pueblo sufriente hay "gracia", es decir, que el pueblo al encarnar la fe en el Crucificado/Resucitado carga con nosotros confiriéndonos nuevos ojos para ver, manos nuevas para trabajar, espaldas para soportar y esperanza de salvación.

En la experiencia de Ellacuría, su labor teológica, más que un esfuerzo por teorizar una experiencia de fe, nació de eso que lo sostuvo y lo mantuvo fiel hasta entregar su vida: contribuir a bajar de la cruz al pueblo crucificado. Como afirman Arango Alzate y Solano Pinzón (2016), "fue ese pueblo el que no solo le dio qué pensar, lo capacitó para pensar, o le enseñó a pensar, sino el que lo sostuvo, lo acompañó y le permitió encontrar la esperanza para continuar su tarea de transformar la realidad" (p. 125).

Con esta motivación, Ellacuría buscó siempre habérselas con la realidad tal cual era, sin velos ni distorsiones, y a la luz de la fe. Sobre este particular afirma:

Entre tantos signos como siempre se dan, unos llamativos y otros apenas perceptibles, hay en cada tiempo uno que es principal, a cuya luz deben discernirse e interpretarse todas las demás. Ese signo es siempre el pueblo históricamente crucificado, que junta a su permanencia la siempre distinta forma histórica de crucifixión. Ese pueblo crucificado es la continuación del Siervo de Yahvé, al que el pecado del mundo sigue quitándole toda figura humana, al que los poderes de ese mundo siguen despojando de todo, le siguen arrebatando hasta la vida, sobre todo la vida. (Ellacuría, 1981, p. 58)

Estas tres dimensiones de la estructura de la inteligencia sentiente de la realidad y la cuarta referida a la dimensión de la gracia, que brota de la experiencia de fe, constituyen un referente por explorar para interpretar la dinámica del seguimiento de Jesús de manera encarnada en la realidad de la histo- 
ria. La misma lectura de las narrativas evangélicas que hablan del seguimiento, adquieren un nuevo sentido cuando se leen en función de las dimensiones antes mencionadas. El seguimiento de Jesús, desde estas cuatro dimensiones se constituye en la manera creyente de inteligir sentientemente la realidad para hacerla signo del Reino entre nosotros.

El desarrollo anterior sitúa las bases del hacer teológico ellacuriano, denotando la raigambre de la inteligencia sentiente zubiriana, su formación filosófica, política y teológica. Pero fundamentalmente lo que este artículo enfatiza es la manera como Ellacuría apropia estos componentes de su formación intelectual y los integra a la vivencia de la realidad del sufrimiento humano que palpó de primera mano en el contexto salvadoreño y latinoamericano.

Una aproximación teológica a su pensamiento en los términos en los cuales se ha venido desarrollando el presente escrito, refleja los trazos epistemológicos para hacer una teología que, según nuestro parecer, tiene los componentes de una Teología de la Liberación en clave de Teología práctica fundamental (Browning, 1991, pp. 1-12). Esta teología deja al descubierto dos gruesos asuntos que serán abordados integralmente en el siguiente y último apartado: el hacer teológico en el contexto histórico de la praxis eclesial, y las condiciones para que este hacer teológico sea cristiano.

\section{El quehacer teológico ellacuriano y su identidad cristiana}

Ellacuría parte de la tesis de que tanto el hacer teológico como el producto teológico son comprendidos y apropiados en el contexto histórico de la praxis eclesial (De Aquino, 2004, pp. 197-220). El carácter histórico de su teología favorece unas condiciones para dar a conocer los legítimos intereses y motivaciones del hacer teológico frente a cuestiones como ¿qué teología?, ¿dónde?, ¿para quién? En palabras de Metz (2002), "quién hace teología, cuándo, dónde y para quién no son hoy preguntas complementarias, sino constitutivas de la teología" (p. 141). 
Ellacuría es consciente de los condicionamientos históricos del hacer teológico para no pasar por alto la pregunta acerca de quién se favorece con su praxis y reflexión. Además, esto conduce a otra cuestión fundamental como es la de qué significa que el hacer teológico deba formular sus problemas, su reflexión y realización en el marco de unas coordenadas histórico-sociales concretas. La conciencia histórica del hacer teológico que Ellacuría apropió del Concilio Ecuménico Vaticano II, la antropología sentiente de Zubiri, el diálogo que su maestro Rahner propició entre la tradición de la fe cristiana y la modernidad, posibilitaron plantearse la pregunta acerca del lugar de Dios en esa realidad de injusticia centroamericana que vivió y padeció hasta el martirio.

Su amplia formación intelectual y su compromiso cristiano lo llevaron a entender que la pertinencia de su hacer teológico frente a esa convulsionada realidad latinoamericana, no se resolvía al modo de otras teologías, acudiendo a la autoridad de la revelación o del magisterio, puesto que ambas fuentes están condicionadas históricamente. En consonancia con Ellacuría, Juan Luis Segundo (1975) enfatiza este carácter histórico y condicionado de la teología, preguntándose: ¿podemos deducir conocimientos ciertos sobre qué hacer, preguntándole a la revelación, independientemente de todo contexto? (pp. 81-88).

En el mismo sentido, Paul Ricoeur (2008) critica aquella comprensión de la fe cristiana que asume la revelación como autoridad derivada "del cuerpo de doctrinas impuestas por el magisterio como regla de ortodoxia" (p. 137). Lo anterior aflora el carácter histórico del hacer teológico, en tanto no se restringe a una apropiación doctrinal ni conceptual, al margen de los contextos. El hacer teológico ellacuriano se centra en la profundización acerca de la compatibilidad entre el carácter histórico de la revelación y el actuar de los seres humanos en unas condiciones sociales concretas. Por esta razón, Ellacuría es crítico de aquellas pretensiones teológicas relativas, de las que derivan ingenuidades valorativas y verdades de cuño autoritario. 
Para Ellacuría (1981), la praxis eclesial "abarca todo el hacer, de algún modo histórico, de la Iglesia, entendida como comunidad de hombres que, de una u otra manera, realizan el reinado de Dios" (pp. 460-461). Esta realización tiene una finalidad comprometida y liberadora, pues el "reinado de Dios encarna el ámbito de praxis, de acción transformadora que compete a la Iglesia en su caminar histórico" (p. 461).

El esfuerzo de dar razón sobre la realización del Reino de Dios se convierte en la tarea fundamental para la teología de la liberación ellacuriana, porque le permite la profundización de la relación entre la praxis eclesial (praxis teologal) y el hacer teológico (teoría teológica). Esta relación entre la praxis y la teorización tiene una finalidad liberadora, a través de la cual la teología proyecta un modo de hacer y conocer, que en otras palabras es la fase epistemológica de una Teología de la liberación o Teología práctica fundamental en clave de liberación (Ellacuría, 2000, pp. 188-215).

Esta interdependencia entre la praxis teologal y la teoría teológica está mediada por la praxis eclesial y la dinámica socio-histórica, pero sin confundirse lo uno con lo otro, pues de ser así podría ocultarse la identidad de la praxis cristiana. Dicha identidad se fundamenta "en la presencia postulada de un algo más en la historia que se hace efectivo en ella" (Ellacuría, 1978, p. 462). En lo desarrollado en este apartado se ha buscado comprender la relación entre la praxis eclesial y la praxis histórica en general. La aclaración de esta problemática es base para abordar otro asunto de importancia en la teología de Ellacuría, como es la identificación de la praxis eclesial en términos de identidad cristiana, ya que no toda praxis eclesial da cuenta de dicha identidad cristiana.

Según Ellacuría, lo propio del hacer teológico es la comunicabilidad y la realización del Reino de Dios en la historia, lo cual no debe pasar por alto sus vínculos con otros componentes, estructuras y tareas del conjunto de la sociedad (De Aquino, 2012, pp. 1324-1349). Pero esta interdependencia entre la praxis eclesial y la praxis del conjunto de la sociedad no debe desdibujar los rasgos de su identidad cristiana. Esta realización es práxica y comprometida 
con la realidad social desde la cual se hace teología, pero no se reduce a una mirada utópica que anticipe un cambio de las estructuras sociales y políticas (De Aquino, 2013, pp. 127-145).

Desde la fe cristiana se abre un horizonte de esperanza acerca de la realización del Reino de Dios en perspectiva de historia de salvación. La reflexión y traducción discursiva de esa realidad humana convulsionada e intervenida por la praxis de la fe cristiana, es lo que Ellacuría entiende como el momento ideológico del hacer teológico.

Más allá de los enfoques peyorativos sobre la ideología, Ellacuría entiende esta fase ideológica de la teología con respecto a la praxis eclesial, como un acto consciente y de reflexión, de cara a las tensiones y conflictos sociales. Es a través de esta mediación reflexiva que el teólogo puede caer en la cuenta de aquel tipo de praxis eclesial que encarna el hacer teológico cristiano. Esta praxis es coherente con el testimonio cristiano en la medida en que asume el seguimiento de Jesús, pues la finalidad de dicho seguimiento es la realización del Reinado de Dios en la historia. Como señala Ellacuría (1978), "si el objeto fundamental de la misión de Jesús fue el Reinado de Dios, debe serlo también de la praxis eclesial y del momento ideológico de esa praxis eclesial" (p. 467).

La realización del Reino de Dios constituye la preocupación fundamental de la praxis eclesial, y consecuentemente de su momento ideológico. Si bien hay un referente evangélico fundamental de lo que Jesús anunció como Reino de Dios, no obstante, esto implica para el hacer teológico una realización histórica (Reinado). En consecuencia, la teología se centra en todo lo que abarca la relación humana con Dios, y todo lo que lleva a la realización histórica de su Reinado.

La profundización teológica del Reinado de Dios no se limita al anuncio evangélico (Kerigma), sino que, además, debe encargarse del problema de su realización histórica (Historicidad). Este asunto es crucial en la teología de la liberación ellacuriana, porque constituye un mensaje crítico para aquellas teologías que limitan su labor al anuncio e interpretación del Reino de Dios, pero que pueden quedarse cortas en el asunto de su realización histórica. Esta 
crítica es importante desde el punto de vista epistemológico y metodológico, porque deja entrever las limitaciones de las teologías que se presentan como de la liberación, pero que en su hacer y reflexión están reducidas a una interpretación.

La teología de la liberación ellacuriana proyecta un talante interdisciplinar, para comprender, analizar, teorizar y trasformar la realidad histórico-social. En este empeño es importante que la teología se apropie no solo de los recursos de la hermenéutica de procedencia filosófica y bíblica, sino también de los métodos, de la crítica y el análisis de las ciencias sociales (Tracy, 1997, pp. 51-75).

A manera de conclusión y en conexión con el marco categorial ellacuriano, a través del cual hemos transitado a lo largo del presente escrito, se muestra la interdependencia entre teoría, praxis, intelección, sensación, seguimiento, Reinado de Dios e historia de salvación. Pero esta aproximación no ha pretendido agotar la reserva de esta propuesta teológica, por lo que también es apertura para preguntas recurrentes y nuevas de cara al pensamiento provocador de Ignacio Ellacuría: ¿Qué significa que la teología de la liberación sea una teología del Reino de Dios? ¿Qué tienen que ver los esfuerzos humanos con miras a una liberación histórica, incluso socio-política, con la inspiración y praxis del Reino de Dios que predicó Jesús? En esta perspectiva histórica en la que confluye el actuar de Dios con los esfuerzos de liberación humanos, ¿Cómo entiende Ellacuría la trascendencia? ¿Cuál es el sentido histórico de la salvación en la teología de la liberación de Ellacuría? ¿Cómo plantear desde este enfoque teológico el diálogo interdisciplinar entre hermenéutica (símbolos, relatos, sentido, comprensión) y las ciencias sociales (métodos, críticas, análisis, teorización) para hacer Teología de la liberación?

Es importante enfatizar que las anteriores preguntas han sido referencia permanente en la estructura transversal del presente escrito, pero es necesario aclarar que la aproximación e identificación de los trazos de un pensamiento como el de Ellacuría, no significa que se haya agotado la riqueza de su propuesta teológica. Por este motivo, más allá de presumir un dominio de 
dicho pensamiento, la pretensión del escrito es más modesta en la medida que su objetivo es establecer las bases epistemológicas y metodológicas en las que se sitúan los cimientos del ejercicio teológico ellacuriano.

Además de esta base epistemológica, nos detenemos en la relación entre la praxis eclesial circunscrita al plano de los creyentes y la praxis histórica que integra toda acción humana en general, para evidenciar la identidad del quehacer teológico ellacuriano. En este es fundamental la complementariedad entre la praxis y la teoría porque, a través de esta relación, Ellacuría establece la clave del compromiso cristiano que conduce a la realización histórica del reinado de Dios. Pero este quehacer que se refleja en la praxis no debe ser la expresión de un simple activismo que recae una y otra vez en la realidad histórica, sino que requiere además de un proceso de reflexión y teorización, que es lo que Ellacuría identifica como momento ideológico de la teología. Sin esta labor discursiva de la teología es muy difícil que esta pueda dar razón de los signos de los tiempos y de la compatibilidad entre el actuar de Dios y el actuar humano en la historia.

Finalmente, es necesario enfatizar que el proyecto teológico ellacuariano se fundamenta en la vinculación de la inteligencia sentiente y el seguimiento. Dichos referentes le confieren el carácter práxico a su teología, en la medida que se convierten en el horizonte hacia el cual tiene que avanzar el creyente en la búsqueda de la realización del Reino de Dios como historia de salvación. Más aún, la teología de Ellacuría que se refleja en este escrito no olvida que el carácter histórico de la revelación, y cuyo referente máximo es la encarnación de Dios hecho hombre en Cristo, no se reduce a la medida del actuar humano, porque de ser así, la gracia o don de Dios sería un simple antropomorfismo. Si bien es importante que el creyente sea consciente de que el actuar de Dios no suple su compromiso y actuar, por otra parte, no debe perder de vista que el carácter tanto histórico como transhistórico de la gracia no se reduce al actuar humano, porque aún en la pasividad humana, Dios actúa. 


\section{Conflicto de interés}

Los autores declaran la inexistencia de conflicto de interés con institución 0 asociación de cualquier índole. Asimismo, la Universidad Católica Luis Amigó no se hace responsable por el manejo de los derechos de autor que los autores hagan en sus artículos, por tanto, la veracidad y completitud de las citas y referencias son responsabilidad de los autores.

\section{Referencias}

Arango Alzate, 0. y Solano Pinzón, 0. (2016). La espiritualidad en Ignacio de Ellacuría. Theologica Xaveriana, 66(181), 123-145. https://doi. org/10.11144/javeriana.tx66-181.eie

Bañón Pinar, J. (1999). Metafísica y noología en Zubiri. Universidad Pontificia de Salamanca.

Benítez, J. A. (s.f.).El legado eclesiológico de Ignacio Ellacuría. Koinonia. http:// servicioskoinonia.org/relat/198.htm.

Biblia de Jerusalén. (2006). Desclée De Brower.

Browning, D. (1991). A Fundamental practical theology. Fortress Press.

Cambridge Dictionary. (s.f.). Fake news. https://dictionary.cambridge.org/es/ diccionario/ingles/fake-news

De Aquino, F. (2004). A teologia como momento ideológico da práxis eclesial. Uma aproximaçao à teologia de Ignacio Ellacuría. Perspectiva Telogica, 36(99), 197-220. https://doi.org/10.20911/21768757v36n99p197/2004

De Aquino, F. (2010). El carácter práxico de la teología: enfoque epistemológico. Teología y Vida, 51(4), 477-499. http://dx.doi.org/10.4067/S004934492010000300002

De Aquino, F. (2012). Teologia e Ciências Sociais. Horizontes, 10(28), 1324-1349. https://doi.org/10.5752/P.2175-5841.2012v10n28p1337-1362 
De Aquino, F. (2013). 0 Lugar social da teologia. Perspectiva teologica, 45(125), 127-145. https://doi.org/10.20911/21768757v45n125p127/2013

Diccionario de la Real Academia de la Lengua (s.f.). Posverdad. http://dle.rae. es/srv/search?m=30\&w=posverdad

Ellacuría, I. (1975). Hacia una fundamentación filosófica del método teológico latinoamericano. En E. Dussel y E. Ruíz Maldonado, Encuentro Latinoamericano de Teología, Liberación y cautiverio, Estudios Centroamericanos (ECA), pp. 609-635.

Ellacuría, I. (1977). Teorías económicas y relación entre cristianismo y socialismo. Concilium, (125), 282-290.

Ellacuría, I. (1978). La teología como momento ideológico de la praxis eclesial. Estudios Eclesiásticos, 207, 457-476.

Ellacuría, I. (1979). La contemplación en la acción de la justicia. Revista Diakonía, (2), 7-14.

Ellacuría, I. (1981). Discernir "el signo" de los tiempos. Diakonía, (17), 57-59.

Ellacuría, I. (1981). La teología como momento ideológico de la praxis eclesial. Estudios Eclesiásticos, 53(207), 457-476.

Ellacuría, I. (1983). Espiritualidad. En C. Floristán \& J. J. Tamayo (Eds.), Conceptos fundamentales de pastoral, (pp. 301-309). Cristiandad.

Ellacuría, I. (1993). Historia de la salvación. Revista Latinoamericana de Teología, 10(28), 3-25.

Garavito Villarreal, D. de J. (2013). La revelación y la actividad humana: recepción teológica de la constitución dei verbum en clave hermenéutica de la apropiación [Tesis doctoral, Pontificia Universidad Javeriana]. https://repository.javeriana.edu.co/handle/10554/16009

González, A. (1997). Estructuras de la praxis: ensayo de una filosofía primera. Trotta. 
González, A. (1999). La praxis humana ante Cristo. En Teología de la praxis evangélica. Ensayo de una teología fundamental, (pp. 250-327). Sal Terrae.

Metz, J. B. (2002). Dios y Tiempo. Nueva teología política. Trotta.

Ricoeur, P. (2008). Fe y filosofía. Problemas del lenguaje religioso. Prometeo Libros.

Samour, H. (2012). Crítica y liberación. Ellacuría y la realidad histórica contemporánea. ADG-N Libros.

Samour, H. (2014). Zubiri y el proyecto de filosofía de la liberación de Ignacio Ellacuría. Revista de Estudios Centroamericanos ECA, 69(737-738), 155-183. https://doi.org/10.51378/eca.v69i737-738.3241

Segundo, J. L. (1975). Liberación de la Teología. Ediciones Carlos Lohlé.

Sobrino, J. (1992). El principio misericordia. Bajar de la cruz a los pueblos crucificados. Sal Terrae.

Sobrino, J. (2005). "El pueblo crucificado" y "la civilización de la pobreza". "El hacerse cargo de la realidad" de Ignacio Ellacuría. Revista Latinoamericana de Teología (UCA), 1(199), 209-228. http://www.redicces.org. sv/jspui/bitstream/10972/3166/1/RLT-2005-066-A.pdf

Sobrino, J. (2006). Extra pauperes nulla salus. Pequeño ensayo utópico-profético. Revista Latinoamericana de Teología (UCA), 23(69), 219-261. https://doi.org/10.51378/rlt.v23i69.5018

Sols Lucía, J. (1999). La teología histórica de Ignacio Ellacuría. Trotta.

Sols Lucía, J. (2014). Las razones de Ellacuría. En el $25^{\circ}$ aniversario del martirio de los jesuitas de la UCA (1989-2014). Cristianisme i Justícia.

Zubiri, X. (1984). Inteligencia sentiente: inteligencia y realidad. Alianza Editorial.

Ellacuría, I. (2000). Escritos teológicos. Tomo I. UCA Editores.

Tracy, D. (1997). Pluralidad yambigüedad. Hermenéutica, religión, esperanza. Trotta. 